\title{
Article
}

\section{Sympathetic Nerve Function Status in Postmenopausal Women}

\author{
Latifa Afrin Dill Naher ${ }^{1}$, Noorzahan Begum², Sultana Ferdousi ${ }^{3}$, Shelina Begum ${ }^{4}$, Taskina Ali ${ }^{5}$
}

\begin{abstract}
Background: Postmenopausal women usually suffer from increased incidence of cardiovascular diseases than premenopausal women. Alterations in autonomic nerve functions often develop in this group of women that commonly affect cardiac vagal control and usually associated with sympathetic hyperactivity. Objectives: To observe the sympathetic nerve function status in postmenopausal women and their relationships with serum estrogen level. Methods: This cross sectional study was carried out in the Department of Physiology, BSMMU, Dhaka from $1^{\text {st }}$ January to 31 $1^{\text {st }}$ December 2007. A total number of 60 apparently healthy subjects of whom 30 were postmenopausal women with age ranged from 45-60 years(group B) and 30 were premenopausal women with age ranged from 20-30 years (group A) were enrolled. Premenopausal women were studied during follicular phase of menstrual cycle.Two simple autonomic nerve function tests, rise of diastolic blood pressure (DBP) during hand grip and fall of systolic blood pressure (SBP) on standing were done to assess sympathetic activity and serum estrogen level was measured in both the groups. Data were analysed by unpaired $t$ test and Pearson correlation coefficient test. Results: Mean resting SBP and DBP were significantly higher $(p<0.001)$ in postmenopausal women than premenopausal women. The mean value of estrogen was significantly $(\mathrm{p}<0.001)$ lower in group $\mathrm{B}$ (postmenopause) than those in group A (premenopause). Fall in systolic blood pressure after standing was significantly $(\mathrm{p}<0.001)$ higher and rise in diastolic blood pressure after sustained handgrip was significantly $(\mathrm{p}<0.001)$ lower in postmenopausal women than those in premenopausal women during their follicular phase of menstrual cycle. Again, rise in diastolic blood pressure after sustained handgrip and fall in systolic blood pressure after standing showed ( $>0.05$ ) negative correlation with estrogen level in the postmenopausal women which was statistically not significant. In addition, regression analysis further revealed significant association of sympathetic activity with estrogen level and age in postmenopausal women. Conclusion: From this study it can be concluded that sympathetic activity is higher in postmenopausal women, which may be related to their low estrogen level and age as well.
\end{abstract}

Key words: Postmenopause, sympathetic nerve functions, estrogen.

J Bangladesh Soc Physiol. 2010 June; 5(1): 40-45 For author affiliations, see end of text.

http://www.banglajol.info/index.php/JBSP

$\mathbf{M}$ Introduction

enopause is a non-reproductive

phase of life in women, where the production of ovarian hormones gradually decreases $^{1,2}$. Alterations in autonomic nerve functions often develop in this group of women that commonly affect cardiac vagal control and usually associated with sympathetic hyperactivity ${ }^{3}$.This alteration of autonomic functions may cause structural and functional

J Bangladesh Soc Physiol. 2010 June; 5(1): 40-45 
changes at the myocardium and large arteries, which consequently directed towards the development of hypertension ${ }^{4,5}$. It may also promote cardiac arrhythmias, which induces left ventricular hypertrophy and reduces the compliance of the large arteries ${ }^{5}$. Moreover, increased sympathetic activity may lead to sudden cardiac death ${ }^{6}$. So, menopausal women may gradually be hypertensive with increased heart rate due to autonomic nerve dysfunction ${ }^{3}$.

In early 1970s Ewing et al. have considered five simple non invasive cardiovascular reflex tests to evaluate the status of cardiovascular autonomic control ${ }^{7}$. Among them fall of systolic blood pressure(SBP) after sudden standing (orthostatic test)and rise of diastolic blood pressure(DBP) during sustained handgrip are the 2 indices of sympathetic nerve function ${ }^{8}$.

In an investigation on sympathetic nerve function status in postmenopausal women Bhat et al. found that fall in systolic blood pressure after standing and rise in diastolic blood pressure during sustained handgrip, have increased significantly in respect to normal established range ${ }^{9}$.

A large number of postmenopausal women our country are at the risk of developing postmenopausal complication including cardiovascular diseases associated with autonomic nerve dysfunctions Recent attention on postmenopausal health has led several countries to study autonomic nerve function status in postmenopausal women and they have demonstrated the relationships of decreased level of estrogen with autonomic nerve dysfunction ${ }^{3,6,9-11}$. However, no such investigation was reported in our country. Therefore, the present study was done to observe the sympathetic nerve function status, one component of autonomic nerve function in healthy Bangladeshi postmenopausal women. It is expected that the out come of the study may help to identify the silent presence of impaired sympathetic nerve function in postmenopausal population and thereby help the physicians to take appropriate measure for prevention of complications.

\section{Methods}

The present cross sectional study was carried out in the Department of physiology, BSMMU, Dhaka from January to December 2007. In this study a total number of 60 apparently healthy subjects were selected, of whom 30 were postmenopausal with age ranged from 45 to 60 years and 30 were premenopause with age ranged from 20 to 30 years. The duration of the natural and surgical menopause was at least one year and they were not under any form of HRT. Premenopausal women were studied during follicular phase of menstrual cycle. Protocol of this study was approved by the Ethical committee of the Department of Physiology. The aim and objectives of the study was explained to each of the subject in details and then written informed consent was taken. A thorough clinical examination of all subjects were done. Height and weight of each subject was measured and BMI was calculated. Under aseptic precaution 5 $\mathrm{ml}$ of blood was collected and serum was prepared for estimation of estrogen level. Sympathetic nerve function of each of the subjects was evaluated by two cardiovascular reflex test. Orthostatic test estimates systolic blood pressure response after sudden standing from lying position and handgrip test measures diastolic blood pressure response to sustained hand grip. Serum estrogen level of each subject was measured by AxSYM method ${ }^{12}$.

Data were analyzed by unpaired student $t$ test, Pearson's correlation coefficient test and multiple regression analysis as applicable. The statistical analysis was done by SPSS program version-11.5.

\section{Results}

Demographic data of the subjects are presented in the Table I.

The mean estrogen level was significantly $(p<0.001)$ lower in group B than those in group A (Figure 1) Resting heart rate was comparable 


\section{Article}

between the groups. But resting systolic and diastolic blood pressures were significantly higher $(\mathrm{p}<0.001)$ in postmenopausal women than those in premenopausal women (Table II). Fall in systolic blood pressure after standing was significantly $(p<0.001)$ higher and rise in diastolic blood pressure after sustained handgrip was significantly $(\mathrm{p}<0.001)$ lower in postmenopausal women compared to premenopausal women during their follicular phase (Figure $2 \& 3$ ).

Again, with serum estrogen level, fall in systolic blood pressure and rise in diastolic blood pressure were negatively correlated in postmenopausal women though all these correlations were statistically non significant (Figure 4\&5). Furthermore, Regression analysis revealed significant association of rise in diastolic blood pressure with age in postmenopausal women. (Table III)

Table I: Age and BMI in different groups $(\mathrm{n}=60)$

\begin{tabular}{lcc}
\hline Variables & $\begin{array}{c}\mathrm{A} \\
(\mathrm{n}=30)\end{array}$ & $\begin{array}{c}\mathrm{B} \\
(\mathrm{n}=30)\end{array}$ \\
\hline Age (years) & $24.30 \pm 3.88$ & $50.53 \pm 3.02$ \\
BMI $\left(\mathrm{kg} / \mathrm{m}_{-}{ }^{2}\right)$ & $20.80 \pm 1.40$ & $22.18 \pm 3.08$ \\
\hline
\end{tabular}

Data are expressed as mean $\pm \mathrm{SD}$.

$\mathrm{A}=$ Premenopause in follicular phase (control group)

$\mathrm{B}=$ Postmenopause (study group)

$\mathrm{n}=$ Total number of subjects

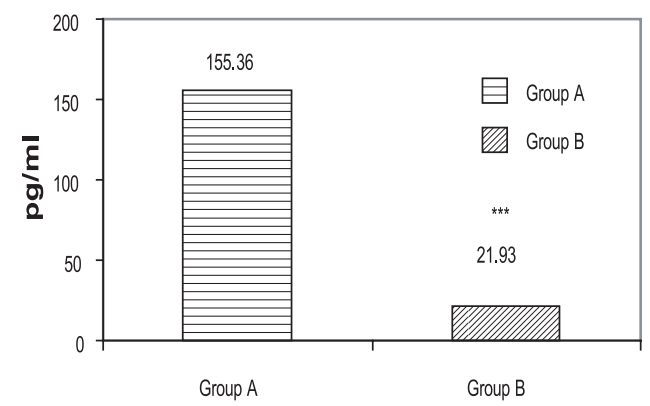

Group A = Premenopause in follicular phase (control) Group B = Postmenopausal (study)

Figure 1: Mean Serum Estrogen Levels in Different Groups ( $\mathrm{n}=60$ )

42
Sympathetic Function in Postmenopausal Women

Table II : Resting Heart Rate and Blood Pressures In Different Groups ( $\mathrm{n}=60$ )

\begin{tabular}{lccc}
\hline Groups & $\begin{array}{c}\text { Heart rate } \\
\text { (beats/min) }\end{array}$ & \multicolumn{2}{c}{$\begin{array}{c}\text { Blood pressure } \\
\text { (mm of Hg) }\end{array}$} \\
\cline { 3 - 4 } & & SBP & DBP \\
\hline A & $77.26 \pm 6.73$ & $100.16 \pm 5.79$ & $67.66 \pm 6.26$ \\
$(\mathrm{n}=30)$ & & & \\
B & $77.80 \pm 7.37^{\text {ns }}$ & $116.66 \pm 14.34^{*}$ & $75.66 \pm 6.78^{*}$ \\
$(\mathrm{n}=30)$ & & & \\
\hline
\end{tabular}

Statistical analysis done by un paired t test

Data are shown as mean \pm SD.

$*=\mathrm{p}<0.001$, ns $=$ not significant, $\mathrm{n}=$ Total number of subjects

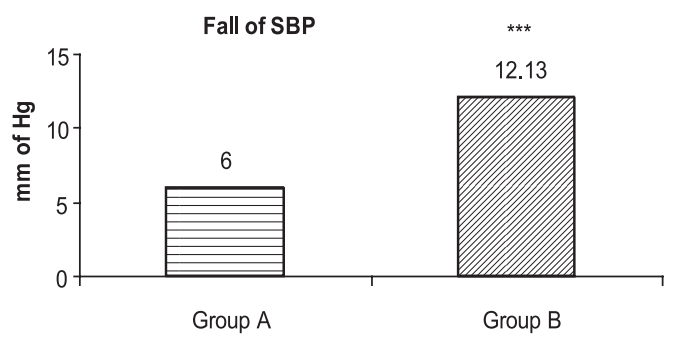

Figure 2: Blood pressure response to standing (fall in SBP) in different groups $(n=60)$

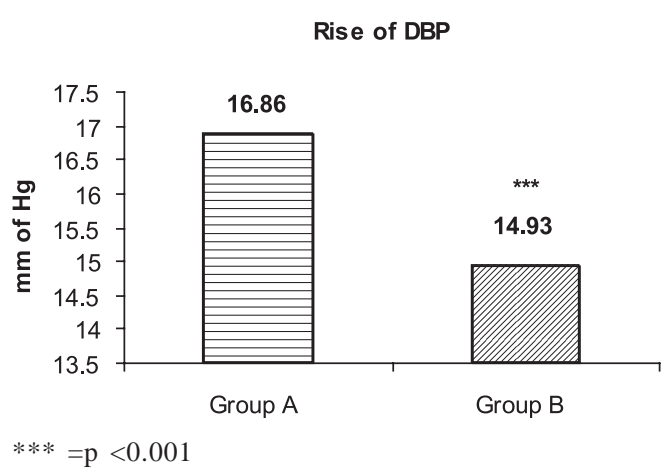

Figure 3: Blood pressure response to sustained handgrip (rise in DBP) in different groups $(n=60)$

J Bangladesh Soc Physiol. 2010 June; 5(1): 40-45 


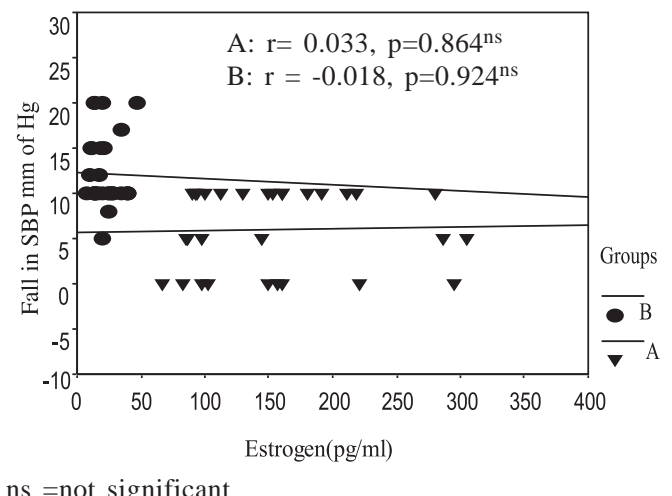

Figure 4: Correlation of fall in systolic blood pressure with serum estrogen level in different groups $(\mathrm{n}=60)$

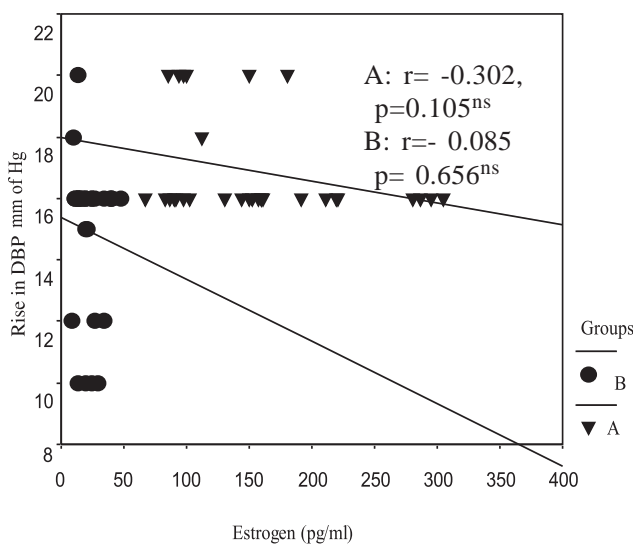

ns =non significant

Figure 5: Correlations of rise in diastolic blood pressure with estrogen level in different groups $(\mathrm{n}=60)$

Table III: Multivariate relations between rise in diastolic BP on sustained handgrip and serum estrogen, age and BMI in postmenopausal $\operatorname{subjects}(\mathrm{n}=30)^{18}$

\begin{tabular}{lll}
\hline $\begin{array}{l}\text { Independent } \\
\text { Variables }\end{array}$ & $\begin{array}{l}\text { Dependant } \\
\text { Variables }\end{array}$ & $\beta / \mathrm{p}$ value \\
\hline $\begin{array}{l}\text { Serum } \\
\text { estrogen }\end{array}$ & $\begin{array}{l}\text { Rise in DBP } \\
\text { during sustained } \\
\text { handgrip }\end{array}$ & $0.016 / 0.932^{\mathrm{ns}}$ \\
Age & & $-0.375 / 0.047^{*}$ \\
BMI & $0.238 / 0.193^{\mathrm{ns}}$ \\
* $^{*} \mathrm{p}<0.05$ & \\
ns $=$ non significant &
\end{tabular}

J Bangladesh Soc Physiol. 2010 June; 5(1): 40-45

\section{Discussion}

In the present study, the observed significantly lower estrogen level in post menopausal is similar to the observations made by other researchers ${ }^{13}$ Again significantly higher resting systolic and diastolic blood pressures in postmenopausal women is consistent to those found by Neves et al ${ }^{11}$ and Scuteri et al $^{14}$.

Significantly higher fall in systolic blood pressure after standing from lying position and significantly lower rise in diastolic blood pressure during sustained handgrip indicate sympathetic hyperactivity in postmenopausal women in comparison to premenopausal women. Similar results were observed by Rosano et al. and Mercuro et al. ${ }^{3,10}$ Again, Neves et al. also made similar observation but they have used spectral analysis of HRV ${ }^{11}$.

Negative correlations of fall in systolic blood pressure and rise in diastolic blood pressure with serum estrogen level in postmenopausal women is similar to those reported by ${ }^{11} \mathrm{Neves}$ et al.

Literatures have cited several factors that might be responsible for this observed higher sympathetic activity and increased resting blood pressure in the postmenopausal women in their estrogen deficient state.

Some group of investigators suggested that estrogen increases density as well as the function of presynptic á adrenoreceptors, which thereby result in significant decrease of NE induced responses $^{15}$. So, estrogen deficiency in postmenopausal women may lead to increased basal level of norepinephrine and its vasoconstrictor responses ${ }^{\mathbf{1 6}}$. Again, estrogen also acts peripherally to increase vasodilatation by increasing the production of NO and prostacycline or by decreasing the release of Endothelin from endothelium ${ }^{17}$. Moreover, estrogen has direct effect on vascular smooth muscle to cause vasodilatation ${ }^{18}$.

Presence of estrogen receptors in cardiomyocytes indicate that it may influence cardiac contractility and regulate heart rate ${ }^{17}$.Therefore estrogen deficiency in postmenopausal women may lead to 
increased vasoconstriction and increased blood pressure due to sympathetic hyperactivity 10,16 .

Rise in diastolic blood pressure during sustained handgrip is the consequence of heart rate dependent increase in cardiac out put and peripheral vasoconstriction. ${ }^{19}$ In elderly women, this less rise in diastolic blood pressure may be due to lower absolute muscle tension ${ }^{20}$, desensitization of $\alpha$-adrenoceptors ${ }^{21,22}$ and decreased $\beta$ adrenergic responsiveness in cardiovascular system 23

Again, a greater fall in systolic blood pressure on standing in elderly person may be related to a decreased heart rate due to down regulation of $\beta_{1}$ adrenergic activity ${ }^{22}$. Moreover, it has been suggested that estrogen increases LDL receptors in the liver ${ }^{17}$. So, deficiency of estrogen in postmenopausal women may cause atherosclerosis due to increased LDL cholesterol in the circulation ${ }^{18}$ which may cause carotid sinus hypersensitivity thereby postural hypotension ${ }^{24}$.

\section{Conclusion}

This study concluded that sympathetic nerve function was abnormally higher in postmenopausal women, which may be related to their age and low estrogen level.

\section{Author Affiliations}

$1 \quad *$ Latifa Afrin Dill Naher, Assistant Professor of Physiology, Prime Medical College, Pirzabad, Badargong Road Rangpur, Bangladesh. E mail: afrin_latifa2007@yahoo.com.

2. Noorzahan Begum, Professor, Department, Department of Physiology, Bangabandhu Seikh Mujib Medical University (BSMMU), Shahbag, Dhaka1000, Bangladesh. Email:noorzahanbeg@yahoo.com

3. Sultana Ferdousi, Assistant Professor, Department of Physiology, Bangabandhu Seikh Mujib Medical University (BSMMU), Shahbag, Dhaka- 1000, Bangladesh. Email: sferdousiratna@gmail.com

4. Shelina Begum, Professor \& Chairman, Department of Physiology, Bangabandhu Seikh Mujib Medical University (BSMMU), Shahbag, Dhaka- 1000, Bangladesh.

5. Taskina Ali, Assistant Professor, Department of Physiology, Bangabandhu Seikh Mujib Medical University (BSMMU), Shahbag, Dhaka- 1000, Bangladesh. E mail: taskina_dr@gmail.com

*For correspondence

\section{Acknowledgement}

The authors acknowledge the financial support from the research grant of Bangladesh University Grant Commission.

\section{References}

1. Staessen JA, Celis H and Fagard R. The epidemiology of the association between hypertension and menopause. J Hum Hyper 1998;12:587-92.

2. Smith KE, Judd HL. Menopause and postmenopause. In: DeCherney AH, Pernoll ML, editors. Current obstetrics and gynaecologic diagnosis and treatment. New York: Appleton and Lange;1994. p. 1-49 .

3. Mercuro G, Podda A, Pitzalis L, Zoncu S, Mascia M, Melis GB, Rosano GM. Evidence of a role of endogenous estrogen in the modulation of autonomic nervous system. Am J Cardiol. 2000; 85:787-89

4. Rosano GMC, Vitale C, Silvestri A, Fini M. Hormone replacement therapy and cardioprotection Ann N Y Acad Sci. 2003;35: 997-99

5. Kotanko P. Cause and Consequences of sympathetic Hyperactivity in Chronic Kidney Disease. Renal Research Institute. 2006; 24:95-9.

6. Pace DT. Effect of postmenopausal hormone replacement therapy on heart rate variability. [Dissertation].[Memphis]:University of Tennessee;1998.111p.

7 Ewing DJ, Martyn CN, Young RJ, Clarke BE. The value of cardiovascular autonomic function tests: 10 years experience in diabetes. Diabetes Care. 1985; 8(5): 491-98.

8 Ewing DJ. Cardiovascular reflexes and autonomic neuropathy. Clin Sci Mol Med. 1978; 55: 321-27

9 Bhat AN,Sadhoo AK,Yograj S,Kaur G. Autonomic functions in Postmenopausal Women. JK science.2005;7(3):135-39.

10. Rosano GMC, Patrizi R, Leonardo F, Ponikowski P, Collins P, Sarrel PM, Chierchia S L. Effect of estrogen replacement therapy on heart rate variablility and heart rate in healthy postmenopausal women. Am J cardiol. 1997; 80:815-17.

11 Neves V F C , Silva de Sa, Gallo Jr L, Catai A M , Martins L E. B, Crescencio J C, Perpetuo N M, Silva E. Autonomic modulation of heart rate of

J Bangladesh Soc Physiol. 2010 June; 5(1): 40-45 
Sympathetic Nerve Function Status in Postmenopausal Women

Article

young and postmenopausal women undergoing estrogen therapy. Braz J Med Biol Res. 2007; 40(4): 491-99.

12 Estradiol Assay,Abbott Laboratories. Diagnostic Division.2004;1-8

13 Fadel PJ, wang Z, Watanabe $\mathrm{H}$, Arbique D, Vongpatanasin W , Thomas GD. Augmented sympathetic vasoconstriction in exercising forearms of postmenopausal women is reversed by oestrogen therapy. J Physiol. 2004; 561(3):893901.

14 Scuteri A, Bos AJG, Brant L J, Talbot L, EdD, Lakatta E G, Fleg JL. Hormone replacement therapy and longitudinal changes in blood pressure in postmenopausal women. Ann Intern Med. 2001; 135(4):229-238.

15 Saleh, TM, Connell BJ. Role of 17 beta-estradiol in the modulation of baroreflex sensitivity in male rats. Am J Physiol. 1998; 275(44):770-78.

16 Sudhir K, Esler, Jennings GL, Komesaroff PA. Estrogen supplementation decreases norepinephrine -induced vasoconstriction and total body norepinephrine spillover in perimenopausal women. Hypertension. 1997; 30: 1538-1543.

17 Saltiki, K, Alevizaki M. Coronary heart disease in postmenopausal women; the role of endogenous estrogen and their receptors. Int J Endocrinol Metab. 2007; 6(1):9-24.
18 Pamidimukkala J, Taylor J.A, Welshons W.V, Lubahn B and Hay M. Estrogen modulation of baroreflex function in conscious mice. Am J Physiol Regul Integr Comp Physiol. 2003;284: 983-89.

19 Lind AR, McNicol GW. Circulatory responses to sustained handgrip contractions performed during other exercise, both rhythmic and static. J Physiol. 1967;192: 595-607.

20 Ewing DJ, Irving JB, Kerr F, Wildsmith JAW, Clarke BF. Cardiovascular responses to sustained handgrip in normal subjects and in patients with diabetes mellitus: a test of autonomic function. Clin Sci Mol Med. 1974; 46:295-306.

21 Gausty B, Weidmann P, Gnädinger MP. Autonomic function tests as related to age and gender in normal man. Klin Wochenschr. 1986; 64: 499-505.

22 Shi X, Wary DW, Formes KJ, Wang H-W,Hayes PM,O-Yurvati AH, Weiss MS, Reese IP. Orthostatic hypotension in aging human. Am J Physiol heart Circ Physiol. 2000; 279: 1548-54.

23 Ford GA, Dachman WD, Blaschke ,Hoffman BB. Effect of aging on beta 2 adrenergic receptor stimulated flux of $\mathrm{K}^{+}, \mathrm{PO}_{4}$,FFA and Glycerol in human forearms. J App Physiol. 1995; 78(1):172-78.

24 Johnson RH. Ageing and the autonomic nervous system. In:SR Bannister and CJ Mathias, (editors). Autonomic Failure A text book of Clinical Disorders of the Autonomic Nervous System. New York: Oxford University press;1992. 903.p 